\title{
Robust and Efficient 'RGB' based Fractal Image Compression: Flower Pollination based Optimization
}

\author{
Gaganpreet Kaur \\ Research Scholar ${ }^{1}$ \& Asst. \\ Professor $^{2}$ \\ ${ }^{1}$ I.K.Gujral P.T.U, Kapurthala, \\ Punjab \\ ${ }^{2}$ SGGSWU, Fatehgarh Sahib, \\ Punjab
}

\author{
Dheerendra Singh, PhD \\ Professor \& Head \\ SUSCET Tangori \\ Mohali, Punjab
}

\author{
Manjinder Kaur \\ Student \\ Dept. of CSE, SGGSWU \\ Fatehgarh Sahib, Punjab
}

\begin{abstract}
Fractal image compression uses the property of selfsimilarity in an image and utilizes the partitioned iterated function system to encode it. Fractal image compression is attractive because of high compression ratio, fast decompression and multi-resolution properties. The main drawback of Fractal Image Compression is the high computational cost and is the poor retrieved image qualities. To overcome this drawback, we design a new algorithm which is based on Pollination Based Optimization which is used to classify the phantom, satellite and rural image dataset. Flower Pollination Based Optimization is nature inspired algorithm which decreases the search complexity of matching between range block and domain block. Also, the optimization technique has effectively reduced the encoding time while retaining the quality of the image. Peak signal to noise ratio, entropy, compression ratio and mean square error is found for phantom, rural and satellite images data set. This new method showed improved highly accurate results.
\end{abstract}

General terms

Optimization, Soft Computing

\section{Keywords}

Pollination Based Optimization (PBO), Fractal Image Compression (FIC), Satellite Image ,Phantom Images, Partitioned Iterated Function System, Range Block, Domain Block, Peak Signal Noise Ratio (PSNR), Mean Square Error (MSE), Compression Ratio, Entropy.

\section{INTRODUCTION}

The foundation of fractal image goes to Barnsley \& Jacquin. In fractal image compression an image is represented by fractals rather than pixel. Block segmentation, region segmentation and the cross searching method lie under the umbrella of selfsimilarity algorithms. A fractal is worked as Iterated Function System which is a group of affine transformations. The main work for fractal coding is to extract the fractals which are used for approximation to the original image. These fractals are represented as a set of affine transformations. It has high compression ratio and simple decompression method. The main drawback is larger computational time for image compression. In order to reduce the computation time different optimization techniques have been proposed. It is found that the computational time can be improved by performing the search in a small sub-set of domain pool rather than over the whole space.

In fractal image compression, the image is divided into a number of block domains with arbitrary size. Then, the image is divided again into block ranges with size less than that of the block domain.

The main objective of this paper is to develop an efficient optimization technique for fractal image compression which involves classifying the domain pool blocks for a gray level image and color image, thus improving the encoding time and quality of images.

In this paper, flower Pollination Based Optimization approach is used for fractal image compression. The paper is organized as follows. In section 2, pollination based Optimization (PBO) is discussed. In section 3, the proposed methodology is discussed. Experimental results on images are presented in section 4. Finally, in Section 5 , some conclusions and directions for future work are discussed.

\section{POLLINATION BASED OPTIMIZATION}

Pollination is a process of transfer of pollen from the male parts of a flower called anther to the female part called stigma of a flower. Pollination is of two types: Biotic and Abiotic pollination.

In biotic pollination pollen is transferred using insects and animals while in abiotic pollination more number of pollinators is required like wind etc. Plants have both male as well as female organs. The transfer of pollen from one plant to other is considered to be good. The floral display, fragrance and nectar attract pollinators, which leads to pollination. The pollination in plants is 6 week programme.

The pollination model used was suggested by Thakar et al. [4] and later modified by Prajakta V. Belsare et. al. [5]. The reproductive success for every plant can be modeled by the following expression:

$$
R=\left(\frac{A \times D}{\alpha+A \times D}\right)+\frac{\left(\frac{\alpha}{\alpha+A \times D}\right) \times N^{P}}{N^{p}+N^{P}}-C(N+D) \ldots
$$

This was further implemented for application of battery charger to generate rule base using fuzzy by Kumar et al. [2]. 


\section{PROPOSED METHODOLOGY \& IMPLEMENTATION}

In this work mean square error is used as fitness function. The image as a whole is taken rather than taking single pixel in image. Image is subdivided into R, $\mathrm{G}$, and $\mathrm{B}$ components. Pollination parameters like average display, nectar content etc. are initialized. Weekly goal for pollination in fractal is determined on the basis of scaling to transform. In each iteration, MSE is calculated for every range block and domain block. Then the probability is calculated for each domain and range block based on MSE.

\subsection{Flower Pollination Based Fractal Image Compression Algorithm}

The PBO algorithm in fractal image compression applied is as:

Step 1: Split the color image into three different matrixes $\mathrm{R}, \mathrm{G}, \mathrm{B}$ and repeat the following steps.

Step 2: Initialize the PBO parameters that includes:

a1=1.2;//Average display

A1 $=0.9 ; / /$ Average Investment in Nectar Content

$\mathrm{D}=1.2 ; / /$ Individual investment in nectar $\mathrm{pb}=3 ; / /$ Parameter related to pollinators learning efficiency

No. of seasons $=20 / / \mathrm{No}$. of iterations

No. of plants $=6 / /$ No. of sub-blocks

No. of weeks $=6 / / \mathrm{No}$. of transformations

Step 3: Resize the image into $256 * 256$ size. Find out the rows and column of the image.

Step 4: Scale the domain block and next generation is calculated using modified equation (1) as:

$\mathrm{R}=\left(\mathrm{a} 1 * \mathrm{D} *\left(\mathrm{pb} .^{\wedge}(\mathrm{i}+\mathrm{j})\right) *(1-\mathrm{pb}) .^{\wedge}(\mathrm{n}-(\mathrm{i}+\mathrm{j}))\right) \cdot /(\mathrm{ri})$

Step 5: Define weekly goal that is matrix of 6 possible scaling to transform

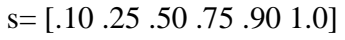

Step 6: Calculate the MSE, in each iteration, for every range block and domain block.

Step 7: Calculate probability of each domain and range block based on the MSE value using equation (2).

$\operatorname{Pi}(n+1)=P i=r 1\left(\right.$ Pbest $\left._{j}-X_{i}\right)+r 2\left(P_{j}-X_{j}\right)$

$X i(n+1)=X i(n)+P i(n+1)$

The $\mathrm{i}^{\text {th }}$ block is represented as $\mathrm{Xj}=(\mathrm{x} 1, \mathrm{x} 2, \ldots \ldots \mathrm{xj})$. The best probability of each block is considered and represented as $\mathrm{P}_{\text {best }_{\mathrm{j}}}=(\mathrm{P} 1, \mathrm{P} 2, \ldots \ldots \ldots \mathrm{Pj})$. The probability of the block among all the values in that iteration is considered as $\mathrm{P}_{\mathrm{j}}$. The probability of block ' $\mathrm{i}$ ' is represented as $p_{j=}\left(p 1, p 2, p 3, \ldots \ldots \ldots p_{j}\right)$.

Step 8: If the probability is above the predefined value than go to step four otherwise stop.

Step 9: If no domain block is left then stop the process otherwise go to next iteration.

\section{RESULTS}

For RGB fractal image compression using flower PBO, large dataset of Phantom, Satellite-Rural and SatelliteUrban images was used for testing phase. Results were calculated after implementing above algorithm in Matlab 7.5.0.

In this work compression time (encoding time) of fractal image compression is reduced and visual quality of image is better as compare to previous fractal image compression schemes, also PSNR provides better result in case of proposed algorithm. The compression is executed in two steps firstly perform compression i.e. image encoding and after encoding decoding of image take place, image is reconstructed and compression ratio and PSNR are calculated.

Table 1, Table 2 and Table 3 shows the Total Time, Mean Square Error, Entropy, Compression Ratio and Peak Signal to Noise Ratio of Phantom images for Robust and Efficient Fractal Image Compression using Flower Pollination based Optimization.

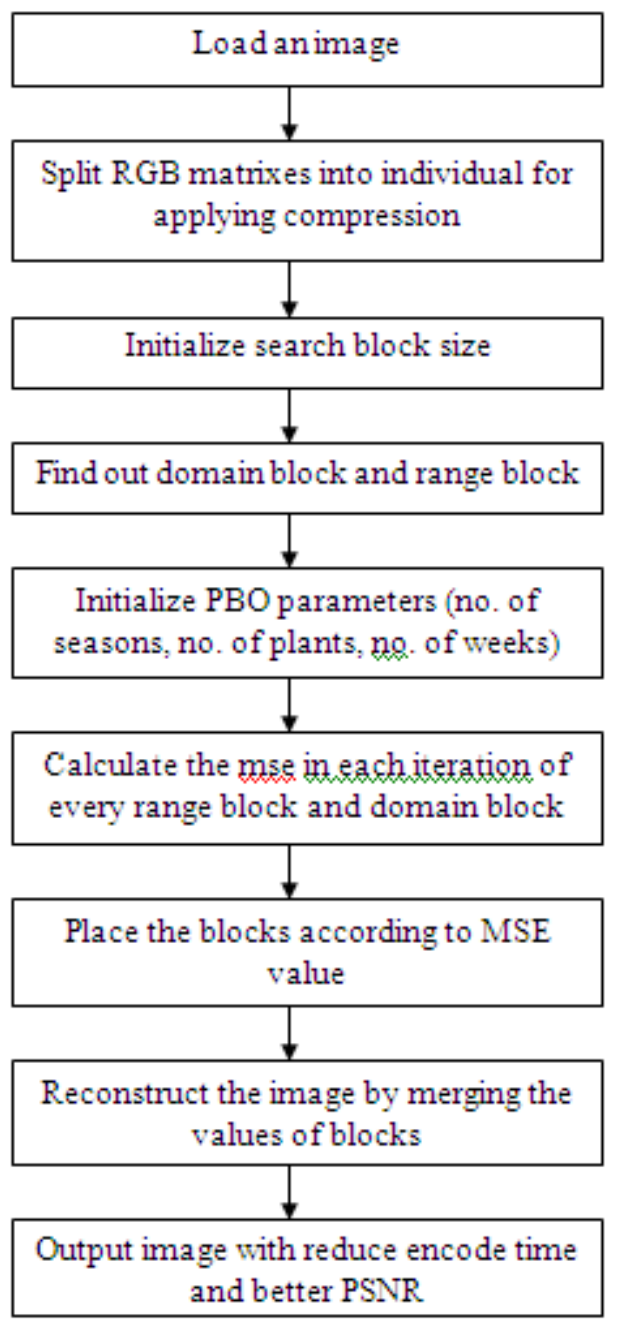

Fig 1: Algorithm level design of fractal image compression using pollination based optimization.

For calculation P1001, P1002, P1003, P1004, P1005, P1006, P1007, P1008, P1009, P10010 phantom images are used. In Table 2, for calculation SR101, SR102, SR103, SR104, SR105, SR106, SR107, SR108, SR109, SR1010 satellite rural images are used. In Table 3, for 
calculation SU101, SU102, SU103, SU104, SU105, SU106, SU107, SU108, SU109, SU1010 satellite urban images are used. All the calculated values are rounded to two decimal digit places.

Table 1. Computation Results of FIC using PBO on Phantom Images

\begin{tabular}{|c|c|c|c|c|c|}
\hline $\begin{array}{c}\text { Phant } \\
\text { om } \\
\text { Image } \\
\text { s }\end{array}$ & $\begin{array}{c}\text { Total } \\
\text { Time } \\
\text { (secs) }\end{array}$ & MSE & Entropy & C R & $\begin{array}{c}\text { PSNR } \\
(\mathbf{d b})\end{array}$ \\
\hline P1001 & 0.64 & 0.19 & 14.22 & 14.97 & 35.20 \\
\hline P1002 & 0.61 & 0.22 & 11.02 & 11.62 & 34.68 \\
\hline P1003 & 0.63 & 0.34 & 13.83 & 10.01 & 32.74 \\
\hline P1004 & 0.64 & 0.30 & 15.37 & 13.17 & 33.28 \\
\hline P1005 & 2.23 & 0.37 & 53.57 & 16.94 & 32.36 \\
\hline
\end{tabular}

Table 2: Computation Results of FIC using PBO on Satellite Rural Images

\begin{tabular}{|l|c|c|c|c|l|}
\hline $\begin{array}{l}\text { Satellite } \\
\text { Rural } \\
\text { Images }\end{array}$ & $\begin{array}{l}\text { Total } \\
\text { Time } \\
\text { (secs) }\end{array}$ & MSE & Entropy & CR & $\begin{array}{l}\text { PSNR } \\
(\mathbf{d b})\end{array}$ \\
\hline SR101 & 7.89 & 0.07 & 109.13 & 26.21 & 39.16 \\
\hline SR102 & 0.64 & 0.11 & 15.03 & 20.71 & 37.68 \\
\hline SR103 & 0.63 & 0.06 & 14.86 & 21.94 & 40.06 \\
\hline SR104 & 0.90 & 0.33 & 21.21 & 14.76 & 32.91 \\
\hline SR105 & 1.61 & 0.05 & 41.89 & 27.07 & 40.65 \\
\hline
\end{tabular}

Table 3: Computation Results of FIC using PBO on Satellite Urban Images

\begin{tabular}{|c|c|c|c|c|c|}
\hline $\begin{array}{l}\text { Satellite } \\
\text { Urban } \\
\text { Images }\end{array}$ & $\begin{array}{l}\text { Total } \\
\text { Time } \\
\text { (seconds) }\end{array}$ & MSE & Entropy & CR & $\begin{array}{l}\text { PSNR } \\
(\mathbf{d b})\end{array}$ \\
\hline SU101 & 1.61 & 0.05 & 41.89 & 27.07 & 40.65 \\
\hline SU102 & 2.14 & 0.00 & 44.42 & 55.43 & 50.18 \\
\hline SU103 & 0.65 & 0.25 & 13.18 & 14.20 & 34.09 \\
\hline SU104 & 0.64 & 0.18 & 15.20 & 15.53 & 35.40 \\
\hline SU105 & 0.66 & 0.36 & 13.65 & 12.62 & 32.51 \\
\hline
\end{tabular}

The Figure 2 (a) and (b) shows the graphical user interfaces for the Robust and Efficient Fractal Image Compression using Flower Pollination Based Optimization for input and decompressed image. Table 4 shows the test images used for the work.

\section{CONCLUSION \& FUTURE WORK}

The present paper presents a new technique which improves the fractal image compression through pollination based optimization. The visual quality of image is much better with PBO as compared to FIC. Image compressed with $\mathrm{PBO}$ optimization is much close to original one, but with FIC distortion comes in the image. PSNR is used here to measure the quality of reconstructed image. It is easy to modify to purposed method for other measures of judging the quality of decoded image. This paper shows that the use of PBO, tends to reduce the encoding time and improves the visual quality of image and overall performance of purposed technique is better than other optimization techniques. The key advantage of this technique is that it is well suited for applications requiring fast access to high- quality images. PBO is a much promising and still young technology that can fit well in many area of the multimedia system's world. In the future the existing work can be enhanced by considering the following points. Any other optimization technique can be implemented on fractal Image Compression. The proposed algorithm can also apply on medical images like MRI, CT scan etc.

\section{REFERENCES}

[1] Binitha, S., Sathya, S Siva. 2012, "A Survey of Bio inspired Optimization Algorithms", International Journal of Soft Computing and Engineering, ISSN: 2231-2307, Volume-2, Issue-2.

[2] Kumar, S., Singh, A. 2012, "Pollination based optimization," Presented at $6^{\text {th }}$ International Multi Conference on Intelligent Systems, Sustainable, New and Renewable Energy Technology and Nanotechnology IISN2012, pp. 269-273.

[3] Kevan, PG., Baker, HG. 1985, "Insects as flower visitors and Pollinators", Ann Rev Entomol, Vol. No. 28, pp. 407-453

[4] Thakar, J.D., Kunte, Krushnamegh., Chauhan, Anisha K., Watve, Aparna V., Watve, Milind G. 2003, "Nectarless flowers: ecological correlates and evolutionary stability", Plant animal interactions, Oecologia , 136,pp.565-570.

[5] Prajakta V., et al. 2009, "The co-optimization of floral display and nectar reward", Journal of Biosciences, Vol No. 34(6), pp 1-5.

[6] Chakrapani, Y., Soundararajan, K. 2008, "Implementation of fractal image compression employing artificial neural Networks", World Journal of Modeling and Simulation IEEE, pp. 287295.

[7] Chakrapani, Y., Soundararajan, K. 2010, "Implementation of fractal image compression employing particle swarm optimization", World Journal of Modeling and Simulation, Vol. 6 , No. 1, pp. 40-46.

[8] Chaurasia, V., Somkuwar, A. 2009, "Speed up Technique for Fractal Image Compression", International Conference on Digital Image Processing, IEEE, pp. 319-326.

[9] Elham,A., Mahdi, Y. "A new approach in fractal image compression based on honey bee mating optimization and quadtreetion", Advances In Data Networks, Communications, Computers.

[10] Hashemian, R., Marivada, S. 2004, "Improved Image Compression Using Fractal Block Coding", IEEE, Vol-2, pp. 544-547. 
[11] Hitashi., Kaur, Gaganpreet., Sharma, Sugandha.2012, "Fractal image compression-a Review", International Journal of Advanced Research in Computer Science and software Engineering.

[12] Kaur, Gaganpreet., Singh, Dheerendra. 2012, "Pollination Based Optimization for Color Image Segmentation," International Journal Of Computer Engineering \& Technology, Volume 3, Issue 2, pp. 407-414.

[14] Kaur, Gaganpreet., et al. 2012, "Implementation of Fractal Image Compression Using BiogeographyBased Optimization", Presented at $6^{\text {th }}$ International Multi Conference on Intelligent Systems, Sustainable, New and Renewable Energy Technology and Nanotechnology, pp.123-126 .

[15] Kung, C.M., Yang, W. S., Ku, C. C., Wang, C. Y. 2008, "Fast Fractal Image Compression Base on Block Property",International Conference on Advanced Computer Theory and Engineering, IEEE, pp 477-481.

[16] Lifeng, Xi., Liangbin, Zhang. 2007, “A Study of Fractal Image Compression Based on an Improved Genetic Algorithm",International Journal of Nonlinear Science Vol.3 ,No.2, pp. 116-124.

[17]Lin. Y., Chen, W.(2012), "Fast Search Strategies for Fractal Image Compression," Journal of Information Science and Engineering 28, pp. 17-30.

[18] Mitra, Suman K., Murthy, C. A., and Malay K. Kundu. 1998, "Technique for Fractal Image Compression Using Genetic Algorithm", IEEE Transactions on image processing, Vol. 7, No. 4, pp.586-593.

[19] Mohamed, Faraoun Kamel., Aoued, Boukeli F. 2005, "Optimization of Fractal Image Compression Based On Genetic Algorithms", 3rd International Conference: Sciences of Electronic, Technologies of Information and Telecommunications, Tunisia.
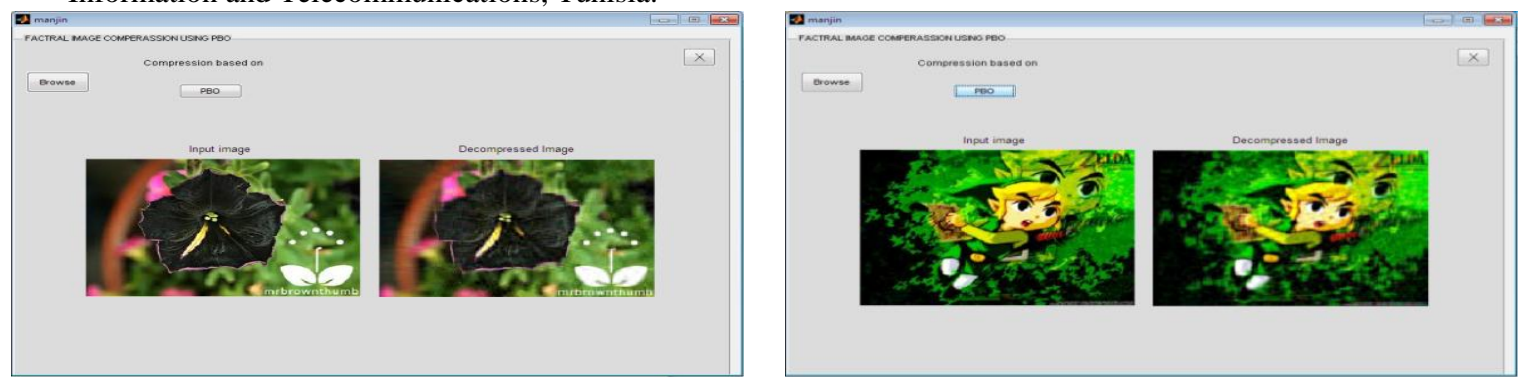

Fig 2: (a) P1001.jpg (b) P1002.jpg (Input \& Decompressed Image)

[20] Shuang, K., Xiao, N., Xu, F., Lv, D., Yu, W. 2008, "Fractal Compression Coding based on fractal dimension feature blocks", International Symposium on Information Science and Engineering, IEEE, pp: 223-226.

[21] Veenadevi, S.V., Ananth, A.G. 2011, "Fractal Image Compression of Satellite Imageries", International Journal of Computer Applications (0975 - 8887) Vol. 30, No.3.

[22]Uma, K., Geetha palanisamy, P., Geetha poornachandran, P. 2011, "Comparison of image compression using GA,PSO and ACO techniques", IEEE-International Conference on Recent Trends in Information Technology, pp: 815-820.

[23]Venkatasekhar,D., Aruna,P., Parthiban,B. 2013, "Fast Search Strategies using Optimization for Fractal Image Compression", International Journal of Computer and Information Technology (ISSN: 2279 - 0764) Volume 02,Issue 03.

[24] Yancong, Y., Ruidong, P. 2011, "Fast Fractal Coding Based on Dividing of Image", IEEE, pp: 14.

[25] Yang,Xin-She. 2012, "Flower Pollination Algorithm for Global Optimization", Lecture Notes in Computer Science Volume 7445, pp 240-249.

[26] Yung,Gi., Wu, Ming-Zhi., Yu-Ling, Wen.2003, "Fractal Image Compression with Variance and Mean”, IEEE ICME, Vol-1, pp 352-356.

[27]Zhao, Yao., Yuan, Baozong. 2001, "A Novel Scheme for Fractal Image Coding", Intelligent Multimedia, Video and Speech Processing, International Symposium, pp. 114-116.

Table 4: Test Images used in the work

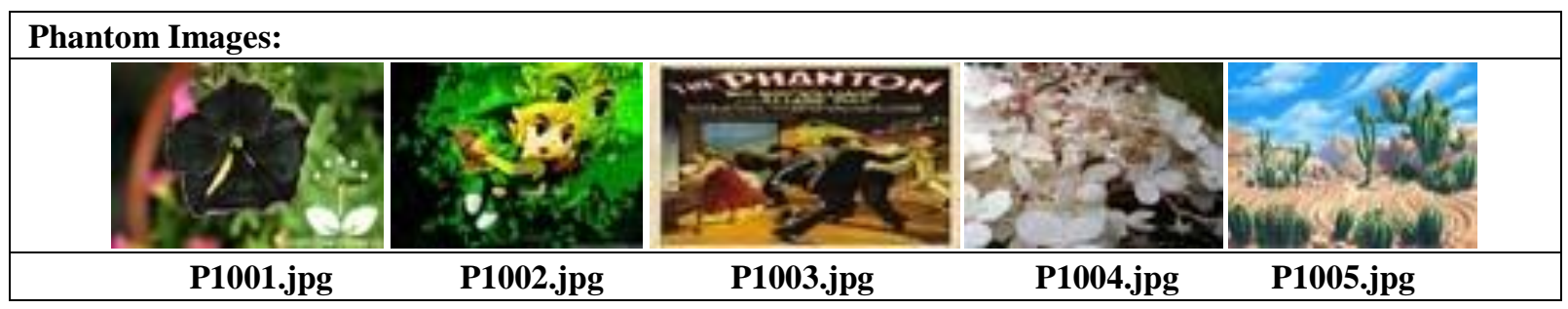




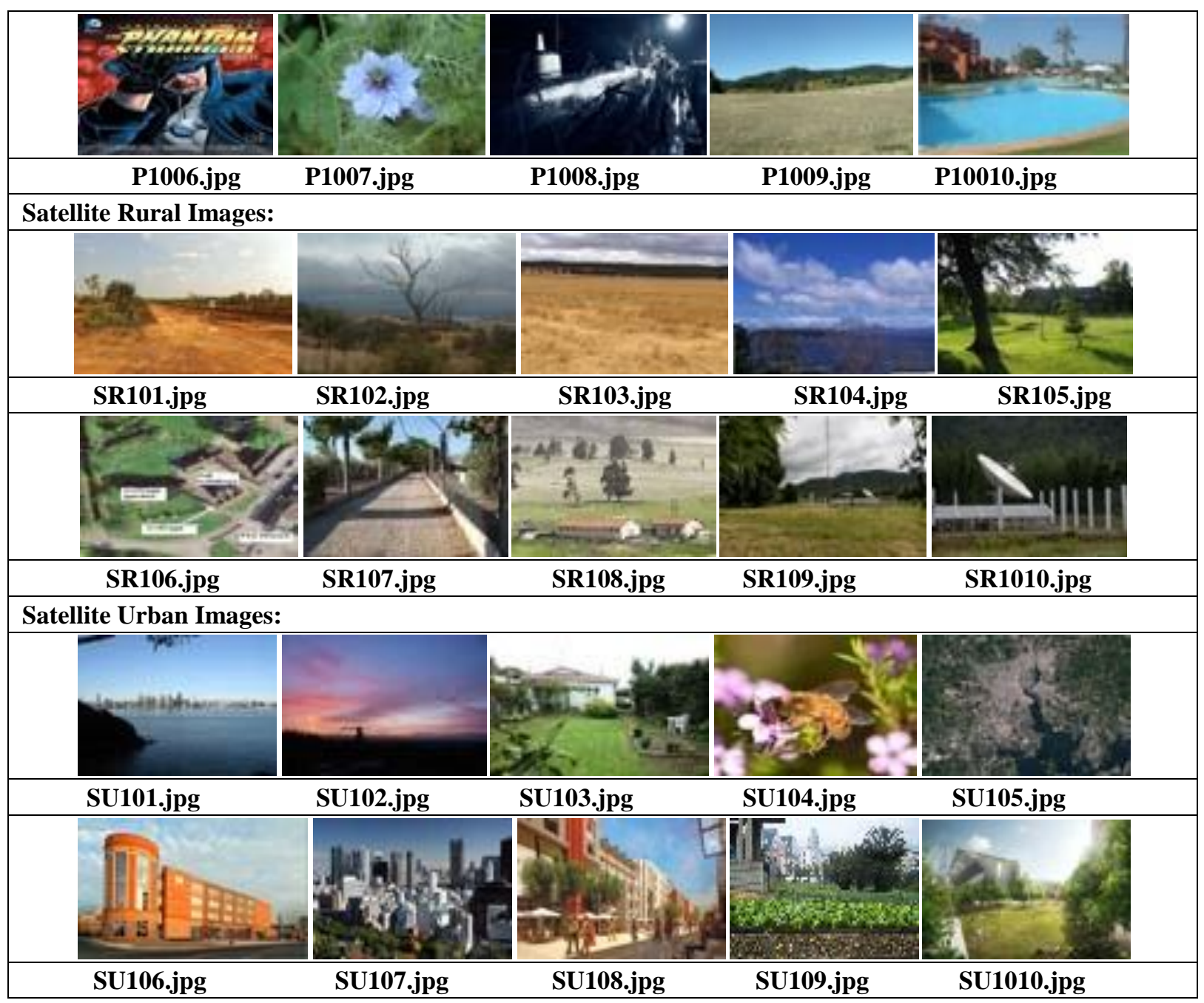

